\title{
The effect of a physiotherapy intervention on disability decrease and on the perceived health-related quality of life in patients with musculoskeletal disorders
}

\author{
DOI: https://doi.org/10.5114/pq.2020.100271 \\ Irini Katsika', George Alexias ${ }^{2}$, Constantinos Togas ${ }^{3}$ \\ ${ }^{1}$ Hellenic Open University, Athens, Greece \\ 2 Department of Psychology, Panteion University of Social and Political Sciences, Athens, Greece \\ ${ }^{3}$ Independent researcher, social worker-psychologist, Megalopolis, Greece
}

\section{Abstract}

Introduction. To evaluate the effect of a physiotherapy intervention on disability decrease and the perceived health-related quality of life (HRQoL) in patients with musculoskeletal disorders.

Methods. The interventional study involved 150 patients of a public hospital and 3 private physiotherapy clinics in Greece. The study lasted 5 months (December 2016-April 2017). A composite questionnaire was used, including sociodemographic/ medical data, Oswestry Disability Index (ODI), and EQ-5D-3L. The main intervention consisted in 10 physiotherapy sessions including transcutaneous electrical nerve stimulation, short-wave diathermy, high-frequency ultrasound, hand massage, and strengthening/stretching exercises. Questionnaires were completed before the first session and then after the tenth session. Analysis was performed with SPSS v. 21.0 .

Results. Half of the participants (50\%) were treated in a state hospital, while the rest $(50 \%)$ in a private clinic. The patients had problems in their spine and neck in the same percentage (44.7\%). There was a significant decrease (mean: 19.33, SD: 13.71) in ODI score after the intervention. The decrease differed significantly depending on age, marital status, and problem location (spine, neck, chest). A significant improvement in EQ-5D-3L and visual analogue scale scores was recorded after treatment $(p=0.001)$. The EQ-5D-3L score change differed significantly depending on age, marital status, educational level, problem location, and previous physiotherapy treatment. There was a significant positive correlation between changes in EQ-5D-3L and ODI $(r=0.48, p<0.001)$

Conclusions. The physiotherapy intervention was beneficial for patients with musculoskeletal disorders and improved their perceived HRQoL. Several demographic and medical characteristics affected the improvement.

Key words: musculoskeletal disorders, physiotherapy intervention, HRQoL, ODI, EQ-5D-3L

\section{Introduction}

Musculoskeletal disorders are common in many countries and include a wide range of inflammatory and degenerative diseases [1]. They have a significant impact on patients' perceived quality of life and incur a significant cost for health systems [2]. In most cases, pain is mechanical and indicates structural or functional disorders of the respective regions. It is mainly associated with disorders of spinal function and stability, especially in the cervical and lumbar spine [3]. Some researchers have shown that in situations where increased loads or complex body postures are expected, muscle imbalance is responsible for changing the spinal column and causing musculoskeletal pain [4].

Chronic musculoskeletal disorders have also a negative effect on the quality of life, as compared with other common chronic conditions [5]. Decreased mobility, the presence of pain/discomfort, and anxiety/depression have been found to constitute important predictors of perceived quality of life [6].

In addition to the physical health consequences, chronic musculoskeletal disorders are associated with mental distress [5] and chronic musculoskeletal pain can have a negative impact on an individual's emotional and social well-being. The number of painful areas seems to be related mostly with the emotional and social dimensions of the perceived quality of life, whereas disease severity has more influence on physical and emotional dimensions. Moreover, pain chronicity exerts a negative effect on all perceived quality of life dimensions [7].

A total of $70-85 \%$ of the general population experience back pain during their lifetime. Such pain is often transient but more than $60 \%$ of patients do not completely recover [8]. The prevalence of neck pain ranges from $20 \%$ to $30 \%$, while back pain occurs in $50-85 \%$ of adults $[6,7]$. It is the third major cause of long-term functional disability in the general population (after rheumatic diseases and cardiovascular problems) and the main reason for long-term absence from work and decreased productivity. It has also a serious impact on psychological aspects and on the patients' perceived quality of life [9]. The main dispositional factors are demographic and socio-economic characteristics, as well as social and psychological factors at workplace [10].

In most cases (> 85\%), it is difficult to establish a definitive diagnosis and treatment [11]. The diagnosis is based mainly on the exclusion of a specific pathology [12].

In order to rationalize the management of back and neck pain, several guidelines have been published in different countries with the aim of relieving symptoms, restoring activities, and preventing a transition to chronic illness [13]. The treatment of back pain and neck pain is predominantly conserva-

Correspondence address: Constantinos Togas, 28 Andrea Labrou Street, Megalopolis, Arcadia, Greece, Postal Code: 22200 , e-mail: togascostas@yahoo.gr 
tive and physiotherapy has a leading role in a variety of therapeutic methods and techniques, such as transcutaneous electrical nerve stimulation (TENS). It is estimated that treatment with TENS produces benefits in almost $60 \%$ of patients, whose pain decreases or disappears completely during the first months [14].

Electrotherapy provides a short-term relief in pain and disability [15]. The use of ultrasound with high-frequency sonic waves exerts thermal and biochemical impact and has positive effects on pain [16]. Handmade application (massage) increases the threshold of pain, possibly through endorphin release and enhancement of local blood flow [17].

Several physical exercises, although they have not presented statistically significant positive results in the acute phase, improve the quality of life in chronic cases [18].

In recent years, scientists have focused not only on reducing symptoms but also on improving the quality of life of patients with musculoskeletal problems [19, 20]. Of particular interest is the assessment of health-related quality of life (HRQoL) by the patients themselves by using various tools. According to the World Health Organization, HRQoL refers to physical, emotional, and social functioning, with the consideration of the general well-being, as it is assessed by each person [21].

Traditionally, the efficacy of musculoskeletal diseases therapy was evaluated on the basis of pain reduction [16]. Over the next few years, several researchers concluded that, in addition to pain, other factors, which might be irrelevant to the condition (such as anxiety; personal, social, family, or economic living conditions; depression; personality; and life situations), affected the quality of life of patients with back pain and neck pain [20].

A study conducted by Adorno and Brasil-Neto [22] showed that there was a statistically significant effect of chronic nonspecific back pain both in the physical and psychological dimensions and perceived quality of life was improved after physiotherapy sessions. In another study, a statistically significant correlation between low back pain, poor perceived quality of life, and depression was found in patients with chronic back pain [23]. Soysal and Aslan [24] observed that levels of physical activity, sleep quality, and depression were significantly correlated in patients with chronic pain in their spinal cord. Moreover, Lin et al. [19] concluded that patients with chronic neck pain had poorer perceived HRQoL and more physical and mental health symptoms than healthy individuals.

This study aims to evaluate the effect of a physiotherapy intervention on reducing pain and improving functionality, physical health, and perceived HRQoL in patients with musculoskeletal disorders. On the basis of the literature review, it was hypothesized that: (a) physiotherapy intervention in chest, neck, and spinal cord decreased disability related to musculoskeletal disorders (hypothesis 1); (b) there were differences in disability related to musculoskeletal disorders depending on demographic (gender, age) and medical (location of the problem etc.) variables (hypothesis 2); (c) physiotherapy intervention in chest, neck, and spinal cord improved the perceived HRQoL (hypothesis 3); (d) there were differences in the perceived HRQoL depending on demographic (gender, age) and medical (location of the problem etc.) variables (hypothesis 4). The criteria for rejecting or not rejecting these hypotheses were the scores in the Oswestry Disability Index (ODI) and the EQ-5D-3L scale.

\section{Subjects and methods}

\section{Procedure}

An interventional study was conducted with a convenience sample of 150 patients treated in a general public hospital and in 3 private physiotherapy clinics in Athens, Greece. The duration of the study was 5 months (December 2016April 2017). A female physiotherapist working as a civil servant in the above public hospital was responsible for the distribution of the questionnaires.

The selection of the sample was held by random sampling of the patients admitted to the public hospital and treated in the private physiotherapy clinics on the basis of the daily program. The participants completed the questionnaires twice: before the first physiotherapy session and after having finished the tenth physiotherapy session. The main intervention was a set of 10 physiotherapy sessions.

\section{Participants}

The sample consisted of 150 patients (59 men and 91 women). The main eligibility/inclusion criterion was suffering from chronic chest, neck, and back pain. Patients with rheumatic diseases or fractures, as well as those who had been operated on in the region of the spinal cord were excluded from the study. All patients took part on a voluntary basis and were not remunerated for their participation. They were informed in detail about the purpose of the study and were given assurance of anonymity and confidentiality of the information provided. Moreover, they were informed that they could stop completing the questionnaire at any time if they wished and that their decision to withdraw would not compromise the standards of the care provided.

\section{Intervention}

The main intervention consisted of 10 physiotherapy sessions performed on a daily basis and in scheduled appointments. The intervention was conducted by 4 experienced physiotherapists (1 per site). Each session lasted about 90100 minutes and the set of 10 sessions was completed within 2 weeks. A combined program was used. First, the patients were subjected to a TENS pain-reduction program (25 minutes). Then, they followed a program that included application of short-wave diathermy (15 minutes), high-frequency ultrasound (20 minutes), and hand massage (15 minutes). Finally, the participants performed strengthening exercises and stretching exercises of the spine muscles (2 sets of 10 repetitions for each exercise with a 5-minute pause).

\section{Assessment}

A composite questionnaire was used, which included sociodemographic and medical data, as well as ODI and EQ-5D-3L. The questionnaires had been translated and culturally adapted to the Greek population by several scholars.

\section{Sociodemographic and medical data}

The patients reported their gender, age, job, marital status, and place of residence. Concerning the medical data, they provided the site of their problem (neck, chest, spine) and stated if they had been subjected to physiotherapy for the same problem in the past and if they performed exercise. 


\section{Oswestry Disability Index}

ODI is a significant instrument for the evaluation of disabilities related to musculoskeletal disorders (especially ones caused by low back pain). It consists of 10 items and is used to assess functionality (disability) in musculoskeletal diseases, especially in acute or chronic low back pain $[25,26]$ (Appendix 1).

The index contains 10 topics concerning intensity of pain, lifting, ability to care for oneself, ability to walk, ability to sit, sexual function, ability to stand, social life, sleep quality, and ability to travel. Each topic category is followed by 6 statements describing different potential scenarios in the patient's life relating to the topic. The patient then checks the statement which most closely resembles their situation, e.g., for 'Pain intensity': I have no pain at the moment $=0$, the pain is very mild at the moment $=1$, the pain is moderate at the moment $=2$, the pain is fairly severe at the moment $=3$, the pain is very severe at the moment $=4$, the pain is the worst imaginable at the moment $=5$ ).

The 10 items of the questionnaire are rated on a 6-point scale (0-5), with higher scores reflecting greater pain and lower functionality. More specifically, value 0 indicates no pain in the first question and great functionality in the remaining 9 questions. On the contrary, value 5 indicates severe pain and very low functionality in daily activities. The total possible score ranges from 0 to 50 . The scores for all questions answered are summed, then multiplied by 2 to obtain the index (range: $0-100$ ). Zero is equated with no disability and 100 is the maximum disability possible. The score in the index is divided into the following categories: 0-20\%: minimal disability, 21-40\%: moderate disability, 41-60\%: severe disability, $61-80 \%$ : crippling back pain, $81-100 \%$ : these patients either are bed-bound or have an exaggeration of their symptoms [26].

ODI is easy to use and the average time for completing it is about 5 minutes. It was developed in the English language and has been translated into many languages, presenting good psychometric properties (reliability, validity, etc.) [25]. In this study, the Greek version of the questionnaire was used [27]; Cronbach's alpha coefficient was equal to 0.78 .

\section{$E Q-5 D-3 L$}

The 3-level version of EQ-5D (EQ-5D-3L) was introduced in 1990 by the EuroQol Group [28] and consists of 2 parts: the $E Q-5 D$ descriptive system and the $E Q$ visual analogue (EQ VAS) scale (Appendix 2). The EQ-5D-3L descriptive system comprises the following 5 dimensions: mobility, self-care, usual activities, pain/discomfort, and anxiety/depression. Each dimension has 3 levels: no problems, some problems, and extreme problems. The patient is asked to indicate their health state by ticking the box next to the most appropriate statement in each of the 5 dimensions. This decision translates into a 1-digit number that expresses the level selected for that dimension. The digits for the 5 dimensions can be combined into a 5-digit number that describes the patient's health state. The EQ VAS records the patient's self-rated health on a vertical VAS, where the endpoints are labelled 'The best health you can imagine' and 'The worst health you can imagine'. The VAS can be used as a quantitative assessment of health outcome that reflects the patient's own judgement. EQ-5D-3L is available in the English language and in more than 170 languages, in various modes of administration. It has also been translated and validated for the Greek population, presenting good psychometric properties
[29]. In this study, the Greek version of the scale was used and Cronbach's alpha coefficient for this scale was equal to 0.79 .

\section{Data analysis}

The statistical program SPSS 21.0 was used for the analysis of the data. The Kolmogorov-Smirnov test served to examine the normality of continuous variables. Before the application of any statistical criterion (e.g. $t$-test), a checking of its assumptions was performed. The analysis included the descriptive statistics first. Pearson's correlation coefficient was used to investigate linear correlation among quantitative variables. Statistically significant differences in certain variables between 2 groups were checked with an independent sample $t$-test, while statistically significant differences between more than 2 groups were checked with ANOVA. In order to compare the scores between the first and the second assessment (before the first physiotherapy session and after having finished the tenth physiotherapy session), a paired samples $t$-test was used.

Moreover, 2 multiple linear regression analyses were conducted, with ODI change score and EQ-5D-3L change score as the dependent variables. Data were examined for violations of independency, normality, linearity, equality of variance, and multicollinearity or singularity existence. An examination for outliers and influential points took place as well, by evaluating the Mahalanobis and Cook distance, centred leverage value, and DFFITS and DFBETAS.

The statistical significance level $(p)$ was set at $5 \%$.

\section{Ethical approval}

The research related to human use has complied with all the relevant national regulations and institutional policies, has followed the tenets of the Declaration of Helsinki, and has been approved by the hospital's Research Ethics Committee and by the clinics' administration boards.

\section{Informed consent}

Informed consent has been obtained from all individuals included in this study.

\section{Results}

The majority of the sample were women (60.7\%), married (64\%), 56-65-year-olds (27.3\%), higher education graduates $(45.3 \%)$, and private employees $(29.3 \%)$ or civil servants (29.3\%). In addition, the vast majority lived in a town (82.7\%) and had civil insurance (88\%). The demographic characteristics of the sample are presented in Table 1.

Half of the participants (50\%) were subjected to physiotherapy treatment in a state hospital, while the other half $(50 \%)$ received physiotherapy treatment in a private clinic. The patients had problems in their spinal cord and in their neck in the same percentage $(44.7 \%)$. No one had undergone an operation for spinal cord problems, while $57.3 \%$ had been previously subjected to physiotherapy treatment for the same problem. The majority of the patients did not exercise (68\%).

The mean ODI score before the physiotherapy intervention was $28.45(S D=15.64$, $\min =4, \max =88$, range $=84)$; after the physiotherapy intervention, it was $9.38(S D=7.46$, $\min =0, \max =44$, range $=44)$. Consequently, there was a significant decrease $($ mean $=19.33, S D=13.71, \min =-16$, $\max =68$, range $=84$ ) in ODI score after the physiotherapy intervention (Figure 1). This decrease was statistically significant according to the paired samples $t$-test $(t=16.20, d f=131$, $p=0.000)$ and indicates a significant decrease in disability. 
Table 1. Demographic characteristics of the participants

\begin{tabular}{|c|c|c|}
\hline Characteristics & $n$ & $\%$ \\
\hline \multicolumn{3}{|l|}{ Gender } \\
\hline Men & 59 & 39.3 \\
\hline Women & 91 & 60.7 \\
\hline \multicolumn{3}{|l|}{ Age } \\
\hline 18-25 years & 6 & 4.0 \\
\hline 26-35 years & 14 & 9.3 \\
\hline $36-45$ years & 34 & 22.7 \\
\hline 46-55 years & 32 & 21.3 \\
\hline 56-65 years & 41 & 27.3 \\
\hline$\geq 66$ years & 23 & 15.3 \\
\hline \multicolumn{3}{|l|}{ Marital status } \\
\hline Single & 33 & 22.0 \\
\hline Married & 96 & 64.0 \\
\hline Divorced & 16 & 10.7 \\
\hline Widow/widower & 5 & 3.3 \\
\hline \multicolumn{3}{|l|}{ Level of education } \\
\hline Primary & 17 & 11.3 \\
\hline Secondary & 65 & 43.3 \\
\hline Higher & 68 & 45.3 \\
\hline \multicolumn{3}{|l|}{ Job } \\
\hline Private employee & 44 & 29.3 \\
\hline Civil servant & 44 & 29.3 \\
\hline Freelancer & 18 & 12.0 \\
\hline Pensioner & 16 & 10.7 \\
\hline Other & 28 & 18.7 \\
\hline \multicolumn{3}{|l|}{ Place of residence } \\
\hline Village & 4 & 2.7 \\
\hline City & 22 & 14.7 \\
\hline Town & 124 & 82.7 \\
\hline \multicolumn{3}{|l|}{ Health insurance } \\
\hline Civil & 132 & 88.0 \\
\hline Private & 7 & 4.7 \\
\hline No & 11 & 7.3 \\
\hline
\end{tabular}

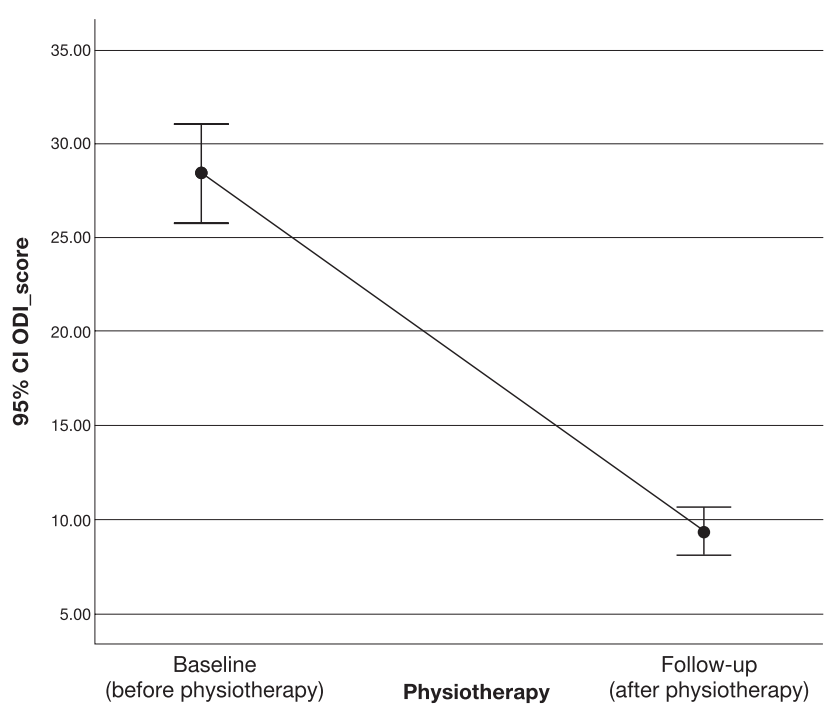

Figure 1. Mean Oswestry Disability Index (ODI) score before and after physiotherapy

The patients were also classified into categories depending on their ODI score before and after the treatment (Table 2). Before the intervention, about half of them (49.6\%) presented moderate disability. After the treatment, a vast majority (93.3\%) exhibited minimal disability. This result indicates that the physiotherapy intervention had a significant impact on decreasing disability.

The decrease in ODI scale differed significantly depending on age and marital status of the participants (Table 3). Specifically, before the physiotherapy intervention, participants who were $\geq 56$ years old had a higher score than those aged $46-55$ years $(p=0.007)$. Participants who were $18-45$ years old had a lower score than those aged $46-55$ years after the physiotherapy intervention $(p=0.004)$. After the treatment, a significant decrease was recorded for all 3 groups $(p<0.001)$. However, the decrease in the participants who were 46-55 years old was so low that it reached almost similar levels as the other 2 groups $(p>0.050)$. In addition, patients who were $18-45$ years old had a significantly lower score than those aged $46-55$ years after the intervention $(p=0.004)$.

Before the intervention, married participants had a significantly lower score than the unmarried ones $(p=0.002)$. After the intervention, a significant decrease was reported in both groups $(p<0.001)$, but the decrease in married patients was so high that finally both groups had a nearly similar score $(p=0.648)$.

The decrease in ODI score differed significantly also depending on the problem location. Before the intervention, participants with neck problems had a lower ODI score than those with spinal problems. After the intervention, a significant decrease in all 3 groups was recorded $(p<0.050)$, but the

Table 2. Frequencies and percentages in Oswestry Disability Index categories before and after treatment

\begin{tabular}{|l|c|c|c|c|}
\hline \multirow{2}{*}{ Category } & \multicolumn{2}{|c|}{ Before treatment } & \multicolumn{2}{c|}{ After treatment } \\
\cline { 2 - 5 } & Frequency & $\%$ & Frequency & 93.3 \\
\hline Minimal disability & 44 & 32.1 & 126 & 5.9 \\
\hline Moderate disability & 68 & 49.6 & 1 & 0.7 \\
\hline Severe disability & 17 & 5.1 & 0 & 0 \\
\hline Bed-bound or symptom exaggeration & 7 & 0.7 & 0 & 0 \\
\hline Total & 1 & 100 & 135 & 100 \\
\hline
\end{tabular}


Table 3. Change in Oswestry Disability Index depending on the demographic characteristics

\begin{tabular}{|c|c|c|c|}
\hline Characteristics & Mean & $S D$ & $p$ \\
\hline \multicolumn{3}{|l|}{ Gender } & 0.071 \\
\hline Men & -21.96 & 14.19 & \\
\hline Women & -17.57 & 13.18 & \\
\hline \multicolumn{3}{|l|}{ Age } & 0.026 \\
\hline 18-45 years & -20.87 & 16.19 & \\
\hline $46-55$ years & -13.31 & 7.10 & \\
\hline$\geq 56$ years & -21.20 & 12.97 & \\
\hline \multicolumn{3}{|l|}{ Marital status } & 0.001 \\
\hline Unmarried & -26.47 & 15.09 & \\
\hline Married & -15.89 & 11.59 & \\
\hline \multicolumn{3}{|l|}{ Level of education } & 0.305 \\
\hline Primary & -14.20 & 7.45 & \\
\hline Secondary & -18.47 & 13.17 & \\
\hline Higher & -20.81 & 14.73 & \\
\hline \multicolumn{3}{|l|}{ Job } & 0.858 \\
\hline Private employee & 19.21 & 15.88 & \\
\hline Civil servant & -20.09 & 16.33 & \\
\hline Freelancer & -16.33 & 6.70 & \\
\hline Pensioner & -18.22 & 6.36 & \\
\hline Other & -20.87 & 10.65 & \\
\hline \multicolumn{3}{|l|}{ Health insurance } & 0.175 \\
\hline Civil & -25.33 & 14.63 & \\
\hline Private & -18.89 & 13.60 & \\
\hline
\end{tabular}

decrease in patients with spinal problems was so high that finally participants with neck problems had a nearly similar score as those with spinal problems $(p>0.050)$. In addition, after the physiotherapy intervention, subjects with neck problems presented a lower score than those with chest problems $(p=0.002)$.

The results for the EQ-5D-3L are presented in Table 4. Among the different EQ-5D-3L dimensions, the majority of the patients had some problems with mobility $(56.7 \%)$, with usual activities $(70.7 \%)$, with pain/discomfort $(78 \%)$, and with anxiety/depression $(70.7 \%)$ before the intervention. On the contrary, most patients had no problems with self-care (52\%). After the intervention, the majority of the participants had no problems with mobility (76\%), with self-care $(87.3 \%)$, with usual activities (80.7\%), and with pain/discomfort (69.3\%). In turn, most of them were moderately anxious/depressed (52\%). All these changes in EQ-5D-3L dimensions were statistically significant $(p<0.001)$. Concerning the general health status, a significant improvement in EQ-5D-3L and VAS scores was recorded after the treatment $(p=0.001)$. The mean score was 0.14 in EQ-5D-3L scale and 68.73 in EQ VAS before the intervention and 0.83 and 86.00 , respectively, after the intervention. These changes indicate an improvement in the general health status of the participants after the physiotherapy sessions.

Before the treatment, the patients' categories (in accordance with their ODI score) differed significantly in VAS score
Table 4. Distribution of EQ-5D-3L dimension responses before and after treatment

\begin{tabular}{|c|c|c|c|}
\hline Dimension & $\begin{array}{c}\text { Before } \\
\text { treatment } \\
n(\%)\end{array}$ & $\begin{array}{c}\text { After } \\
\text { treatment } \\
n(\%)\end{array}$ & $p$ \\
\hline \multicolumn{3}{|l|}{ Mobility } & 0.001 \\
\hline No problems & $63(42 \%)$ & $114(76 \%)$ & \\
\hline Some problems & $85(56.7 \%)$ & $36(24 \%)$ & \\
\hline Confined to bed & $2(1.3 \%)$ & $0(0 \%)$ & \\
\hline \multicolumn{3}{|l|}{ Self-care } & 0.001 \\
\hline No problems & $78(52 \%)$ & $131(87.3 \%)$ & \\
\hline Some problems & $71(47.3 \%)$ & $19(12.7 \%)$ & \\
\hline $\begin{array}{l}\text { Unable to wash or dress } \\
\text { myself }\end{array}$ & $1(0.7 \%)$ & $0(0 \%)$ & \\
\hline \multicolumn{3}{|l|}{ Usual activities } & 0.001 \\
\hline No problems & $32(21.3 \%)$ & $121(80.7 \%)$ & \\
\hline Some problems & $106(70.7 \%)$ & $28(18.7 \%)$ & \\
\hline $\begin{array}{l}\text { Unable to perform } \\
\text { any usual activities }\end{array}$ & $12(8.0 \%)$ & $1(0.7 \%)$ & \\
\hline \multicolumn{3}{|l|}{ Pain/discomfort } & 0.001 \\
\hline No pain/discomfort & $3(2.0 \%)$ & $104(69.3 \%)$ & \\
\hline Moderate pain/discomfort & $117(78.0 \%)$ & $45(30 \%)$ & \\
\hline Extreme pain/discomfort & $30(20.0 \%)$ & $1(0.7 \%)$ & \\
\hline \multicolumn{3}{|l|}{ Anxiety/depression } & 0.001 \\
\hline Not anxious/depressed & $34(22.7 \%)$ & $72(48 \%)$ & \\
\hline $\begin{array}{l}\text { Moderately anxious/ } \\
\text { depressed }\end{array}$ & $106(70.7 \%)$ & $78(52 \%)$ & \\
\hline \multirow[t]{2}{*}{$\begin{array}{l}\text { Extremely anxious/ } \\
\text { depressed }\end{array}$} & $10(6.7 \%)$ & $0(0 \%)$ & \\
\hline & Mean $(S D)$ & Mean $(S D)$ & $p$ \\
\hline EQ visual analogue scale (\%) & $68.73(4.22)$ & $86.00(4.92)$ & 0.001 \\
\hline EQ-5D-3L (score) & $0.14(0.32)$ & $0.83(0.16)$ & 0.001 \\
\hline
\end{tabular}

( $F=6.75, p=0.001)$. Patients with minimal disability had a significantly higher score $(M=70.68)$ than those with moderate disability $(M=68.53)$ and severe disability $(M=65.88)$. After the intervention, there were no significant differences.

The effects of age group, marital status, and level of education were statistically significant in EQ-5D-3L score change ( $p=0.01, p=0.03, p=0.049$, respectively) (Table 5). Participants who were $>55$ years old had a significantly lower increase in the score (i.e. lower improvement) than those aged 18-45 years and $45-55$ years. In addition, married participants had a greater increase in the score (i.e., greater improvement) than the unmarried ones, and patients with secondary education had a greater increase in the score (i.e., greater improvement) than those with primary education $(p=0.039)$.

Concerning the medical characteristics of the patients, location of the problem and previous physiotherapy interventions for the same problem significantly affected the change in EQ-5D-3L score, too $(p=0.01$ and $p=0.049$, respectively).

There was a significant positive correlation between changes in EQ-5D-3L and ODI $(r=0.48, p<0.001)$, that is, 
Table 5. Change in EQ-5D-3L depending on the demographic and medical characteristics

\begin{tabular}{|c|c|c|c|}
\hline Characteristics & Mean & $S D$ & $p$ \\
\hline \multicolumn{4}{|l|}{ Gender } \\
\hline Men & 0.72 & 0.40 & 0.46 \\
\hline Women & 0.37 & 0.42 & \\
\hline \multicolumn{3}{|l|}{ Age group } & $0.001^{*}$ \\
\hline $18-45$ years & 0.80 & 0.35 & \\
\hline $46-55$ years & 0.78 & 0.46 & \\
\hline$\geq 56$ years & 0.55 & 0.39 & \\
\hline \multicolumn{3}{|l|}{ Marital status } & $0.003^{*}$ \\
\hline Married & 0.56 & & \\
\hline Unmarried & 0.76 & & \\
\hline \multicolumn{3}{|l|}{ Level of education } & $0.043^{*}$ \\
\hline Primary & 0.46 & 0.42 & \\
\hline Secondary & 0.74 & 0.41 & \\
\hline Higher & 0.69 & 0.39 & \\
\hline \multicolumn{3}{|l|}{ Job } & 0.055 \\
\hline Private employee & 0.71 & 0.44 & \\
\hline Civil servant & 0.72 & 0.40 & \\
\hline Freelancer & 0.82 & 0.38 & \\
\hline Pensioner & 0.42 & 0.43 & \\
\hline Other & 0.66 & 0.32 & \\
\hline \multicolumn{3}{|l|}{ Health insurance } & 0.615 \\
\hline Civil & 0.63 & 0.37 & \\
\hline Private & 0.69 & 0.41 & \\
\hline \multicolumn{4}{|c|}{ Location of the problem } \\
\hline Neck & 0.82 & 0.36 & $0.001^{*}$ \\
\hline Chest & 0.34 & 0.45 & \\
\hline Spine & 0.64 & 0.39 & \\
\hline \multicolumn{4}{|c|}{ Previous physiotherapy treatment for the same problem } \\
\hline Yes & 0.63 & 0.45 & $0.049^{*}$ \\
\hline No & 0.76 & 0.33 & \\
\hline
\end{tabular}

${ }^{*} p<0.05$

the lower the ODI change, the higher the EQ-5D-3L change was.

According to the multiple linear regression, the location of the problem and marital status were associated with ODI score change (Table 6). Specifically:

- Participants with neck problems had a lower decrease in ODI score $(\beta=10.26)$ than those with spinal problems.

- Participants with chest problems had a lower decrease $(\beta=8.96)$ than those with spinal problems.

- Married participants had a lower decrease $(\beta=9.17)$ than unmarried ones.

In addition, the location of the problem, age, and ODI change were associated with EQ-5D-3L score change (Table 7). Specifically:

- Participants with spine problems had a greater increase $(\beta=0.36)$ than those with chest problems.
Table 6. Multiple linear regression with ODI change as the dependent variable

\begin{tabular}{|c|c|c|c|c|}
\hline & & \\
\hline & & $\beta+$ & SE++ & $p$ \\
\hline \multirow{3}{*}{ Problem location } & \multicolumn{4}{|l|}{ Spine* } \\
\hline & Neck & -10.26 & 2.22 & $0.001^{* *}$ \\
\hline & Chest & -8.96 & 3.54 & $0.013^{* *}$ \\
\hline \multirow{2}{*}{ Marital status } & \multicolumn{4}{|l|}{ Married* } \\
\hline & Unmarried & -9.17 & 2.25 & $0.001^{* *}$ \\
\hline
\end{tabular}

* reference category, ${ }^{* *} p<0.05$

Table 7. Multiple linear regression with EQ-5D-3L change as the dependent variable

\begin{tabular}{|c|c|c|c|c|}
\hline & & $\beta+$ & SE ++ & $p$ \\
\hline \multirow{3}{*}{ Problem location } & \multicolumn{4}{|l|}{ Chest $^{*}$} \\
\hline & Spine & 0.36 & 0.09 & $0.001^{* *}$ \\
\hline & Neck & 0.36 & 0.09 & $0.001^{* *}$ \\
\hline \multirow{3}{*}{ Age } & \multicolumn{4}{|l|}{$\geq 56$ years $^{*}$} \\
\hline & 18-45 years & 0.20 & 0.06 & $0.002^{* *}$ \\
\hline & $46-55$ years & 0.15 & 0.07 & $0.04^{* *}$ \\
\hline
\end{tabular}

* reference category, ${ }^{* *} p<0.05$

- Participants with neck problems had a greater increase $(\beta=0.36)$ than those with chest problems.

- Participants who were 18-45 years old had a greater increase $(\beta=0.20)$ than those aged $>55$ years.

- Participants who were 46-55 years old had a greater increase $(\beta=0.15)$ than those aged $>55$ years.

\section{Discussion}

The present study was conducted in order to examine the perceived HRQoL of patients suffering from musculoskeletal problems and the efficacy of a physiotherapy intervention both in disability and in general health status of these patients.

The results showed that there was a significant correlation between musculoskeletal pain and disability. Disability was also improved after the physiotherapy intervention, as patients before the treatment had moderate levels of disability (level 2 according to ODI), and after the intervention, there was a decrease in the minimum level of disability (level 1 according to ODI). These results confirm hypothesis 1 and are consistent with those reported in other studies [2, 19, 24], which indicated a high correlation between pain and disability in patients with musculoskeletal diseases and a significant improvement in patients' functionality after physiotherapy intervention.

In addition, hypothesis 2 was confirmed. After the physiotherapy intervention, a decrease in ODI score differed significantly depending on age, marital status, and problem location. With regard to age, participants aged $\geq 56$ years had greater disability than the 2 younger age groups before and after the physiotherapy sessions. A significant decrease in all 3 groups was recorded after the physiotherapy intervention. Married participants had significantly greater disability than unmarried patients at first. However, a significant decrease in both groups was recorded after the physiotherapy intervention. Moreover, participants with back pain presented 
significantly greater disability than those with chest and neck pain. But a significant decrease in the score was recorded in all 3 groups after the physiotherapy intervention, indicating a significant relief among the subjects. These results are similar to those reported in other studies [1, 30].

Concerning the general health status, there was a significant increase in both EQ-5D-3L and VAS scale scores after the physiotherapy intervention, indicating an improvement in the health status. Consequently, hypothesis 3 was confirmed.

There were differences in EQ-5D-3L change depending on age, marital status, and the location of the participants' problem, confirming hypothesis 4 . Specifically, it was found that the score of the patients who were $>55$ years old presented a significantly lower decrease than in the younger age groups, implying a lower improvement in the general health status. Moreover, married participants had a significantly higher improvement than unmarried ones. Concerning the location of the problem, it was found that patients with spine and neck problems had a lower score in EQ-5D-3L scale before the treatment than patients with chest problems. After the physiotherapy intervention, a significant increase in all 3 groups was recorded, but the increase in participants with chest problems was lower than in the other 2 groups, which had the same high score in this scale after the physiotherapy intervention. These findings confirm hypothesis 3 and are consistent with those reported in other studies that examined the effect of physiotherapy in disability and quality of life [20, 22, 24].

The results of this study clearly indicate that the performed physiotherapy intervention is a useful and significant practice for patients with musculoskeletal problems, concerning the relief of their symptoms and the improvement of their perceived HRQoL.

\section{Limitations}

A significant limitation of this study is the fact that the stability of the improvement in functionality and perceived HRQoL and the long-term effects of the intervention were not examined.

\section{Conclusions}

The perceived HRQoL of patients with musculoskeletal disorders seems to be improved after the applied physiotherapy intervention. According to the results of this study, the intervention was beneficial for patients with back pain, neck pain, and chest pain, without a specific aetiology; pain, disability, and general health were improved after the treatment. Several demographic and medical characteristics affected the improvement.

Notwithstanding the above limitation, the results of the research are useful to make suggestions for implementation of physiotherapy practice in patients with musculoskeletal disorders. These patients have serious functionality problems and their perceived HRQoL is poor. It is therefore necessary to recognize these vulnerable individuals (on the basis of the found risk factors) and to implement physiotherapy for their support.

Future research is suggested to investigate the effect of the performed physiotherapy intervention on the perceived HRQoL of patients with musculoskeletal disorders. Similar research can be conducted with different research designs (e.g. cohort studies) and with larger samples in order to examine the long-term effects of this intervention.

\section{Disclosure statement}

No author has any financial interest or received any financial benefit from this research.

\section{Conflict of interest}

The authors state no conflict of interest.

\section{References}

1. Ezra D, Masharawi Y, Salame K, Slon V, Alperovitch-Najenson D, Hershkovitz I. Demographic aspects in cervical vertebral bodies' size and shape (C3-C7): a skeletal study. Spine J. 2017;17(1):135-142; doi: 10.1016/j. spinee.2016.08.022.

2. Thiese MS, Hegmann KT, Wood EM, Garg A, Moore JS, Kapellusch J, et al. Prevalence of low back pain by anatomic location and intensity in an occupational population. BMC Musculoskelet Disord. 2014;15:283; doi: 10.1186/1471-2474-15-283.

3. Punnett L, Wegman DH. Work-related musculoskeletal disorders: the epidemiologic evidence and the debate. J Electromyogr Kinesiol. 2004;14(1):13-23; doi: 10.1016/ j.jelekin.2003.09.015.

4. Loughenbury PR, Tsirikos Al, Gummerson NW. Spinal biomechanics - biomechanical considerations of spinal stability in the context of spinal injury. Orthop Trauma. 2016;30(5):369-377;doi:10.1016/j.mporth.2016.07.010.

5. Antonopoulou MD, Alegakis AK, Hadjipavlou AG, Lionis CD. Studying the association between musculoskeletal disorders, quality of life and mental health. A primary care pilot study in rural Crete, Greece. BMC Musculoskelet Disord. 2009;10:143; doi: 10.1186/1471-247410-143.

6. Kyriakopoulos S, Papageorgiou DE, Stroubouki T, Stavropoulou A, Ntinou E, Galanopoulos J, et al. Quality of life of patients with musculoskeletal disorders in a Greek hospital. Ethics Biol Eng Med. 2013;4(4):269-284; doi: 10.1615/.2014011858.

7. Wittkopf PG, Zomkowski K, Cardoso FL, Sperandio FF. The effect of chronic musculoskeletal pain on several quality of life dimensions: a critical review. Int J Ther Rehabil. 2017; 24(8):327-336; doi: 10.12968/ijtr.2017.24. 8.327.

8. Machado GC, Ferreira PH, Maher CG, Latimer J, Steffens D, Koes BW, et al. Transient physical and psychosocial activities increase the risk of nonpersistent and persistent low back pain: a case-crossover study with 12 months follow-up. Spine J. 2016;16(12):1445-1452; doi: 10.1016/j.spinee.2016.08.010.

9. Thompson DP, Oldham JA, Woby SR. Does adding cognitive-behavioural physiotherapy to exercise improve outcome in patients with chronic neck pain? A randomised controlled trial. Physiotherapy. 2016;102(2):170-177; doi: 10.1016/j.physio.2015.04.008.

10. Stranjalis G, Tsamandouraki K, Sakas DE, Alamanos Y. Low back pain in a representative sample of Greek population: analysis according to personal and socioeconomic characteristics. Spine. 2004;29(12):1355-1361; doi: 10.1097/01.brs.0000127181.59012.1c.

11. Gandhi T. Comparison of classification-based cognitive functional therapy for patients with chronic low back pain with standard physiotherapy treatment. Physiotherapy. 2016;102(Suppl. 1):E172; doi: 10.1016/j.physio.2016.10. 204.

12. Koes BW, van Tulder MW, Thomas S. Diagnosis and treatment of low back pain. BMJ. 2006;332(7555):14301434; doi: 10.1136/bmj.332.7555.1430. 
13. Bekkering GE, Hendriks HJM, Koes BW, Oostendorp RAB, Ostelo RWJG, Thomassen JMC, et al. Dutch physiotherapy guidelines for low back pain. Physiotherapy. 2003;89(2):82-96; doi: 10.1016/S0031-9406(05)60579-2.

14. Coutaux A. Non-pharmacological treatments for pain relief: TENS and acupuncture. Joint Bone Spine. 2017; 84(6):657-661; doi: 10.1016/j.jbspin.2017.02.005.

15. Mayer JM, Mooney V, Matheson LN, Erasala GN, Verna JL, Udermann BE, et al. Continuous low-level heat wrap therapy for the prevention and early phase treatment of delayed-onset muscle soreness of the low back: a randomized controlled trial. Arch Phys Med Rehabil. 2006;87(10):1310-1317; doi: 10.1016/j.apmr.2006.07. 259.

16. Gam AN, Warming S, Larsen LH, Jensen B, Høydalsmo O, Allon I, et al. Treatment of myofascial trigger-points with ultrasound combined with massage and exercise - a randomised controlled trial. Pain. 1998;77(1):73-79; doi: 10.1016/s0304-3959(98)00084-0.

17. Kumar S, Beaton K, Hughes T. The effectiveness of massage therapy for the treatment of nonspecific low back pain: a systematic review of systematic reviews. Int J Gen Med. 2013;6:733-741; doi: 10.2147/IJGM.S50243.

18. Hides JA, Jull GA, Richardson CA. Long-term effects of specific stabilizing exercises for first-episode low back pain. Spine. 2001;26(11):E243-E248; doi: 10.1097/000 07632-200106010-00004.

19. Lin R-F, Chang J-J, Lu Y-M, Huang M-H, Lue Y-J. Correlations between quality of life and psychological factors in patients with chronic neck pain. Kaohsiung J Med Sci. 2010;26(1):13-20; doi:10.1016/S1607-551X(10)70003-6.

20. Kovacs FM, Abraira V, Zamora J, Gil del Real MT, Llobera J, Fernández $\mathrm{C}$, et al. Correlation between pain, disability, and quality of life in patients with common low back pain. Spine. 2004;29(2):206-210; doi: 10.1097/01. BRS.0000107235.47465.08.
21. Burckhardt CS, Anderson KL. The Quality of Life Scale (QOLS): reliability, validity, and utilization. Health Qual Life Outcomes. 2003;1:60; doi: 10.1186/1477-7525-1-60.

22. Adorno MLGR, Brasil-Neto JP. Assessment of the quality of life through the SF-36 questionnaire in patients with chronic nonspecific low back pain. Acta Ortop Bras. 2013; 21(4):202-207; doi:10.1590/S1413-78522013000400004.

23. Dündar Ü, Solak Ö, Demirdal ÜS, Toktaş H, Kavuncu V. Relation of pain, disability and depression with quality of life in patients with chronic low back pain [in Turkish]. Genel Tip Derg. 2009;19(3):99-104.

24. Soysal ANO, Aslan UB. Treatment of chronic neck pain by two combined physiotherapy programs: comparison of phonophoresis and ultrasound. Asian Biomed. 2013;7(6):821-827; doi: 10.5372/1905-7415.0706.245.

25. Davidson M, Keating JL. A comparison of five low back disability questionnaires: reliability and responsiveness. Phys Ther. 2002;82(1):8-24; doi: 10.1093/ptj/82.1.8.

26. Fairbank JC, Pynsent PB. The Oswestry Disability Index. Spine. 2000;25(22):2940-2952; doi: 10.1097/00007632 $-200011150-00017$.

27. Boscainos PJ, Sapkas G, Stilianessi E, Prouskas K, Papadakis SA. Greek versions of the Oswestry and RolandMorris disability questionnaires. Clin Orthop Relat Res. 2003;411:40-53; doi: 10.1097/01.blo.0000068361.471 47.79 .

28. EuroQol Group. EQ-5D-3L. Available from: https://euroqol.org/eq-5d-instruments/eq-5d-3l-about/.

29. Kontodimopoulos N, Pappa E, Niakas D, Yfantopoulos J, Dimitrakaki C, Tountas Y. Validity of the EuroQoL (EQ-5D) instrument in a Greek general population. Value Health. 2008;11(7):1162-1169; doi:10.1111/j.1524-4733.2008. 00356.x.

30. Moseley L. Combined physiotherapy and education is efficacious for chronic low back pain. Aust J Physiother. 2002;48(4):297-302; doi: 10.1016/s0004-9514(14)60169-0.

\section{Appendix 1. Oswestry Disability Index}

\section{Section 1: Pain intensity}

- I have no pain at the moment

- The pain is very mild at the moment

- The pain is moderate at the moment

- The pain is fairly severe at the moment

- The pain is very severe at the moment

- The pain is the worst imaginable at the moment
Section 6: Standing

- I can stand as long as I want without extra pain

- I can stand as long as I want but it gives me extra pain

- Pain prevents me from standing for more than 1 hour

- Pain prevents me from standing for more than 30 minutes

- Pain prevents me from standing for more than 10 minutes

- Pain prevents me from standing at all

\section{Section 7: Sleeping}

- My sleep is never disturbed by pain

- My sleep is occasionally disturbed by pain

- Because of pain, I have less than 6 hours sleep

- Because of pain, I have less than 4 hours sleep

- Because of pain, I have less than 2 hours sleep

- Pain prevents me from sleeping at all

\section{Section 8: Sex life (if applicable)}

- My sex life is normal and causes no extra pain

- My sex life is normal but causes some extra pain

- My sex life is nearly normal but is very painful

- My sex life is severely restricted by pain

- My sex life is nearly absent because of pain

- Pain prevents any sex life at all

- Pain prevents me from lifting heavy weights, but I can manage light to medium weights if they are conveniently positioned

- I can lift very light weights

- I cannot lift or carry anything at all 


\section{Section 4: Walking \\ - Pain does not prevent me from walking any distance \\ - Pain prevents me from walking more than 1 mile \\ - Pain prevents me from walking more than 1/2 mile \\ - Pain prevents me from walking more than 100 yards \\ - I can only walk using a stick or crutches \\ - I am in bed most of the time}

\section{Section 5: Sitting}

- I can sit in any chair as long as I like

- I can only sit in my favourite chair as long as I like

- Pain prevents me from sitting more than 1 hour

- Pain prevents me from sitting more than 30 minutes

- Pain prevents me from sitting more than 10 minutes

- Pain prevents me from sitting at all

\section{Section 9: Social life}

- My social life is normal and gives me no extra pain

- My social life is normal but increases the degree of pain

- Pain has no significant effect on my social life apart from limiting

my more energetic interests, e.g. sport

- Pain has restricted my social life and I do not go out as often

- Pain has restricted my social life to my home

- I have no social life because of pain

\section{Section 10: Travelling}

- I can travel anywhere without pain

- I can travel anywhere but it gives me extra pain

- Pain is bad but I manage journeys over 2 hours

- Pain restricts me to journeys of less than 1 hour

- Pain restricts me to short necessary journeys under 30 minutes

- Pain prevents me from travelling except to receive treatment

Appendix 2. EQ-5D-3L

\begin{tabular}{|l|}
\hline $\begin{array}{l}\text { Under each heading, please tick the ONE box } \\
\text { that best describes your health TODAY }\end{array}$ \\
\hline Mobility \\
\hline No problems \\
\hline Some problems \\
\hline Confined to bed \\
\hline Self-care \\
\hline No problems \\
\hline Some problems \\
\hline Unable to wash or dress myself \\
\hline Usual activities \\
\hline No problems \\
\hline Some problems \\
\hline Unable to perform any usual activities \\
\hline Pain/discomfort \\
\hline No pain/discomfort \\
\hline Moderate pain/discomfort \\
\hline Extreme pain/discomfort \\
\hline Anxiety/depression \\
\hline Not anxious/depressed \\
\hline Moderately anxious/depressed \\
\hline Extremely anxious/depressed \\
\hline
\end{tabular}

\section{Visual analogue scale}

- This scale is numbered from 0 to 100

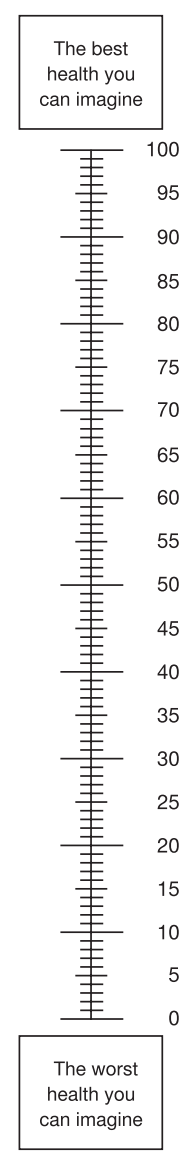

- 100 means the best health you can imagine

- 0 means the worst health you can imagine. Mark an $X$ on the scale to indicate how your health is TODAY

- Now, please write the number you marked on the scale in the box below

YOUR HEALTH

TODAY $=$ 